\title{
An observational study on the impact of the socio-economic crisis in greece on ICU patient recruitment
}

\author{
S Savvidou*, K Marmanidou, M Oikonomou, D Matamis \\ From ESICM LIVES 2015 \\ Berlin, Germany. 3-7 October 2015
}

\section{Introduction}

The recent ongoing financial crisis in Greece has resulted in an overall significant reduction in road traffic accidents, severe injuries and deaths. [1] On the other hand, there is conflicting data about the rate of suicides and suicidal attempts [2], [3].

\section{Objectives}

To investigate the impact of the Greek socioeconomic crisis that started in 2010 on the ICU and hospital admissions due to traffic accident related multiple trauma (MT) and admissions after suicidal attempt (SA).

\section{Methods}

"Papageorgiou" General Hospital is one of the four major hospitals of Thessaloniki, the second largest Greek city of 1.2 million inhabitants. Data was extracted from hospital databases (ICD-10 diagnoses V01-V89 for MT and X60-X84 for SA) from the year 2008 to 2014. Several variables concerning patient demographics, APACHE and SAPS II scores, length of ICU stay (LOS) and outcome were recorded and further statistically analyzed using $\chi\left[^{2}\right]$, Mann-Whitney and Kruskal-Wallis tests.

\section{Results}

During 2008-2014 the hospital has welcomed an average of $100.2+4.7 \times 10^{3}$ patients annually, with an increasing trend. The general adult multidisciplinary ICU has 10 beds, $92.4 \%$ percentage of mechanically ventilated patients and an average admission rate of $392.4+41.6$ patients per year. Over the study period, 262 patients with MT and 66 patients after SA were admitted in

'Papageorgiou' General Hospital of Thessaloniki, ICU, Thessaloniki, Greece
ICU. MT patients were $79.8 \%$ males, mean age $40+19.3$ years old, median LOS 10 days (interquartile range 4-22), mean APACHE score 10.9+6.6, mean SAPS II $37.6+16.7$, overall mortality $16.8 \%$ with 48 h mortality of $7.6 \%$. SA patients were $62.1 \%$ females, mean age $43.1+15$, median LOS 2 days (interquartile range 1-4), mean APACHE score $13.3+7.3$, mean SAPS II $44.7+13.8$,overall mortality $9.1 \%$ with 48 hortality of $6.1 \%$. There was a significant decrease $(-45.5 \%$ in total or $-7.59 \%$ per year) in the admission rate of MT along with a significant increase $(+68.9 \%$ in total or $+11.49 \%$ per year) in the admission rate of SA (actual numbers and trend-lines shown in Figure 1). Statistical analysis revealed associations of mortality with age $(p=0.001$

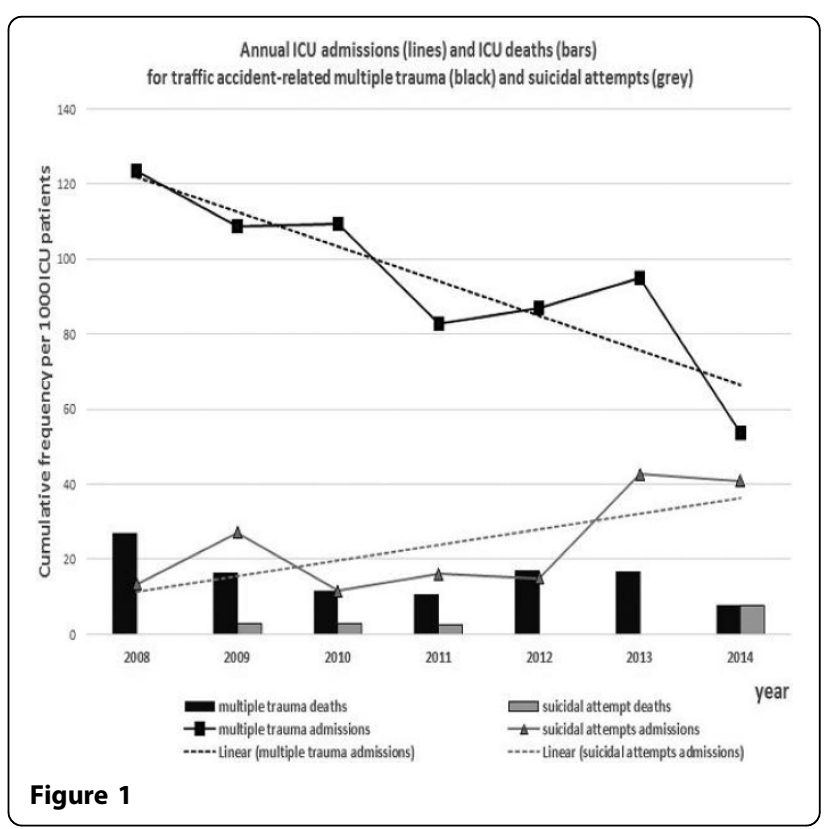

C 2015 Savvidou et al.; This is an Open Access article distributed under the terms of the Creative Commons Attribution License (http:// creativecommons.org/licenses/by/4.0), which permits unrestricted use, distribution, and reproduction in any medium, provided the original work is properly cited. 
for MT and $\mathrm{p}=0.016$ for SA) and with both scoring systems $(\mathrm{p}<0.001)$. No statistical significant differences of gender, age, LOS and mortality were recorded over time.

\section{Conclusions}

The financial crisis in Greece has resulted in a gradual and ongoing decrease in ICU admissions of patients with multiple trauma after severe traffic accident and a parallel increase in admissions after suicidal attempt. Overall mortality has been kept constant over time.

Published: 1 October 2015

\section{References}

1. Michas $G$, et al: Road traffic accidents in Greece: have we benefited for the financial crisis? J Epidemiol Community Health 2013, 67:894.

2. Vlachadis N, et al: Greece's economic crisis and suicide rates: overview and outlook. J Epidemiol Community Health 2014, 1-2.

3. Fountoulakis $\mathrm{KN}$, et al: Rate of suicide and suicide attempts in Thessaloniki Greece (2000-2012). J Affect Disord 2015, 174:131-6.

doi:10.1186/2197-425X-3-S1-A137

Cite this article as: Savvidou et al:: An observational study on the impact of the socio-economic crisis in greece on ICU patient recruitment. Intensive Care Medicine Experimental 2015 3(Suppl 1):A137.

\section{Submit your manuscript to a SpringerOpen ${ }^{\odot}$ journal and benefit from:}

- Convenient online submission

- Rigorous peer review

- Immediate publication on acceptance

- Open access: articles freely available online

- High visibility within the field

- Retaining the copyright to your article 